\title{
Analysis of a Periodic Impulsive Predator-Prey System with Disease in the Prey
}

\author{
Lianwen Wang and Zhijun Liu \\ Department of Mathematics, Hubei University for Nationalities, Enshi, Hubei 445000, China \\ Correspondence should be addressed to Zhijun Liu; zhijun_liu47@hotmail.com
}

Received 13 June 2013; Accepted 5 September 2013

Academic Editor: XianHua Tang

Copyright (C) 2013 L. Wang and Z. Liu. This is an open access article distributed under the Creative Commons Attribution License, which permits unrestricted use, distribution, and reproduction in any medium, provided the original work is properly cited.

\begin{abstract}
We investigate a periodic predator-prey system subject to impulsive perturbations, in which a disease can be transmitted among the prey species only, in this paper. With the help of the theory of impulsive differential equations and Lyapunov functional method, sufficient conditions for the permanence, global attractivity, and partial extinction of system are established, respectively. It is shown that impulsive perturbations contribute to the above dynamics of the system. Numerical simulations are presented to substantiate the analytical results.
\end{abstract}

\section{Introduction}

As a relatively new branch of study in theoretical biology, ecoepidemiology can be viewed as the coupling of ecology and epidemiology. Ecoepidemiological model is more appropriate than the ecological model (or epidemiological model) when species spreads the disease and is predated by other species. Following Anderson and May [1] who were the first to propose an ecoepidemiological model, a number of sophisticated predator-prey models with disease in prey population only are extensively investigated in the ecoepidemiological literature (see [2-5]).

Notice that periodic phenomenon often occurs in many realistic ecoepidemiological models. The effect of a periodically varying environment is important for evolutionary theory as the selective forces on systems in a fluctuating environment differ from those in a stable environment. Nicholson [6] has suggested that any periodic change of climate tends to impose its period upon oscillations of internal origin or to cause such oscillations to have a harmonic relation to periodic climatic changes. Thus, it is reasonable to assume that the coefficients in the systems are periodic functions. On the other hand, in reality, many evolution processes are characterized by the fact that they experience changes of state suddenly. These processes are subject to short-term perturbations whose duration is negligible in comparison with the duration of the process. Consequently, the abrupt changes can be well approximated as impulses. A natural description of the motion of impulsive processes can be expressed by impulsive differential equations. Some impulsive equations have been introduced in ecoepidemiological models in relation to chemotherapeutic [7] and vaccination $[8,9]$ and population disease control $[10,11]$.

Considering the above facts, in this paper, we will consider a periodic predator-prey model subject to impulsive perturbations, in which a disease can be transmitted among the prey species only. Our motive comes from a delayed nonautonomous predator-prey system with disease in the prey in [5], and we consider the effect of impulsive perturbations on a corresponding undelayed periodic version in this paper. Here, we will establish the sufficient conditions for the permanence and partial extinction of the system by using the theory of impulsive differential equations and inequality analytical technique. By Lyapunov functional method, we will also establish sufficient conditions for the global attractivity of the system.

\section{Assumptions and Formulation of Mathematical Model}

The periodic predator-prey model with disease in the prey which is studied in this paper is the system of impulsive 
differential equations below. To formulate the mathematical model, we need to make the following assumptions which are the same as those in [5].

(A1) All newborns are susceptible in the model, in which only susceptible prey is capable of reproducing with logistic law while the infected species does not recover or become immune. The disease only spreads among the prey species and it is not genetically inherited.

(A2) The mortality terms for susceptible and infected prey are density dependent, and both contribute to population growth toward the environmental carrying capacity.

(A3) The predator species hunts on susceptible and infected prey with possibly different predation rates. For example, in some situations, the infected individuals may be caught easily, but the predators eat more fewer infected ones in other situations.

Considering the above basic assumptions, we can now construct the following dynamic system:

$$
\begin{aligned}
& S^{\prime}(t)=S(t)\left[r(t)-k_{1}(t)(S(t)+I(t))\right. \\
& \left.-a_{1}(t) P(t)-\beta(t) I(t)\right], \\
& I^{\prime}(t)=I(t)\left[\beta(t) S(t)-k_{2}(t)(S(t)+I(t))-a_{2}(t) P(t)\right], \\
& P^{\prime}(t)=P(t)\left[-d(t)-b(t) P(t)+c_{1}(t) S(t)+c_{2}(t) I(t)\right], \\
& S\left(\tau_{k}^{+}\right)=\left(1+\alpha_{k}\right) S\left(\tau_{k}\right), \\
& I\left(\tau_{k}^{+}\right)=I\left(\tau_{k}\right)+p \text {, } \\
& P\left(\tau_{k}^{+}\right)=\left(1+\gamma_{k}\right) P\left(\tau_{k}\right) \text {, } \\
& t=\tau_{k}, k \in \mathbb{N} \text {. } \\
& t \neq \tau_{k}
\end{aligned}
$$

Here, $S(0)>0, I(0)>0, P(0)>0 . r(t)$ is intrinsic birth rate function of the susceptible prey species $S(t), d(t)$ is death rate function of the predator species $P(t), k_{1}(t), k_{2}(t)$, and $b(t)$ represent the self-inhibition rate functions of the susceptible prey species $S(t)$, the infected prey species $I(t)$, and the predator $P(t)$, respectively. $\beta(t)$ is the infection rate. $a_{1}(t), a_{2}(t)$ and $c_{1}(t), c_{2}(t)$ denote the capturing rates and conversion rates, respectively. The parameters $r(t), d(t), k_{1}(t)$, $k_{2}(t), b(t), a_{1}(t), a_{2}(t), c_{1}(t)$, and $c_{2}(t)$ are positive continuous $\omega$-periodic functions. The fixed impulsive points satisfy $0=$ $\tau_{0}<\tau_{1}<\tau_{2}<\cdots$ and $\lim _{k \rightarrow \infty} \tau_{k}=+\infty$ for $k \in \mathbb{N}=$ $\{1,2, \ldots\}$. For two real number sequences $\left\{\alpha_{k}\right\}$ and $\left\{\gamma_{k}\right\}$, there is an integer $q>0$ such that $\tau_{k+q}=\tau_{k}+\omega, \alpha_{k+q}=\alpha_{k}>-1$, $\gamma_{k+q}=\gamma_{k}>-1$ for $k \in \mathbb{N}$. The jump conditions reflect the possibility of impulsive effects on the prey and predator. For biological reality, it is natural to assume $\alpha_{k}>-1, \gamma_{k}>-1$ and $p>0$. An obvious example of ecological situation giving rise to system (1) concerns the impulsive harvesting and stocking of the above species; that is, when $\alpha_{k}>0, \gamma_{k}>0, p>0$, the impulsive perturbations stand for stocking while $\alpha_{k}<0$, $\gamma_{k}<0$ mean harvesting.

The organization of this paper is as follows. In the next section, we present some notations and preliminary lemmas. In Section 4, we establish sufficient conditions for the permanence, global attractivity of positive solutions, and partial extinction for the above system, respectively. Several concrete examples and numerical simulations are also presented to substantiate the analytical results in the last section.

\section{Notations and Preliminary Lemmas}

Before establishing our main results, we summarize several useful lemmas for the later sections.

Let $\mathbb{R}=(-\infty,+\infty)$. Denote by $P C(\mathbb{R}, \mathbb{R})$ the set of functions $v: \mathbb{I} \rightarrow \mathbb{R}$ which are continuous for $t \in \mathbb{J}$, $t \neq \tau_{k}$, are continuous from the left for $t \in \mathbb{J}$, and have discontinuities of the first kind at the points $\tau_{k} \in \mathbb{J}$. Denote

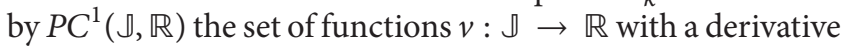
$d v / d t \in P C(\mathbb{I}, \mathbb{R})$.

Lemma 1 (see [12]). Let the function $v \in P C^{1}(\mathbb{J}, \mathbb{R})$ satisfy the inequalities

$$
\begin{gathered}
v^{\prime}(t) \leq g(t) v(t)+h(t), \quad t \neq \tau_{k}, t \geq \tau_{0} \\
v\left(\tau_{k}^{+}\right) \leq d_{k} v\left(\tau_{k}\right)+\beta_{k}, \quad k \in \mathbb{N}
\end{gathered}
$$

where $g(t), h(t) \in C(\mathbb{J}, \mathbb{R}), d_{k}>0$, and $\beta_{k}$ are constants for $k \in \mathbb{N}$. Then for $t \geq \tau_{0}$,

$$
\begin{aligned}
v(t) \leq & v\left(\tau_{0}\right) \prod_{\tau_{0}<\tau_{k}<t} d_{k} \exp \left\{\int_{\tau_{0}}^{t} g(s) d s\right\} \\
& +\sum_{\tau_{0}<\tau_{k}<t}\left(\prod_{\tau_{0}<\tau_{j}<t} d_{j} \exp \left\{\int_{\tau_{k}}^{t} g(s) d s\right\}\right) \beta_{k} \\
& +\int_{\tau_{0}}^{t} \prod_{s<\tau_{k}<t} d_{k} \exp \left\{\int_{s}^{t} g(r) d r\right\} h(s) d s .
\end{aligned}
$$

Analogously, one sees that

$$
\begin{aligned}
v(t) \geq & v\left(\tau_{0}\right) \prod_{\tau_{0}<\tau_{k}<t} d_{k} \exp \left\{\int_{\tau_{0}}^{t} g(s) d s\right\} \\
& +\sum_{\tau_{0}<\tau_{k}<t}\left(\prod_{\tau_{0}<\tau_{j}<t} d_{j} \exp \left\{\int_{\tau_{k}}^{t} g(s) d s\right\}\right) \beta_{k} \\
& +\int_{\tau_{0}}^{t} \prod_{s<\tau_{k}<t} d_{k} \exp \left\{\int_{s}^{t} g(r) d r\right\} h(s) d s,
\end{aligned}
$$

for $t \geq \tau_{0}$, when all the inequalities of (1) are reversed.

Lemma 2 (see $[13,14])$. Consider the following single-species impulsive model:

$$
\begin{gathered}
x^{\prime}(t)=m(t) x(t), \quad t \neq \tau_{k}, k \in \mathbb{N}, \\
x\left(\tau_{k}^{+}\right)=x\left(\tau_{k}\right)+p,
\end{gathered}
$$


where $x(0)>0$, the constant $p>0, m(t)$ is a continuous $\omega$-periodic function satisfying $\int_{0}^{\omega} m(t) d t<0$, and there is an integer $q>0$ such that $\tau_{k+q}=\tau_{k}+\omega, k \in \mathbb{N}$. System (5) has a unique positive $\omega$-periodic solution which is globally asymptotically stable.

Lemma 3 (see [15]). Consider the following impulsive system:

$$
\begin{gathered}
x^{\prime}(t)=x(t)[m(t)-n(t) x(t)], \quad t \neq \tau_{k}, k \in \mathbb{N}, \\
x\left(\tau_{k}^{+}\right)=x\left(\tau_{k}\right)+p,
\end{gathered}
$$

where $x(0)>0, n(t)>0$, the constant $p>0$, and $m(t), n(t)$ are continuous $\omega$-periodic functions. Assume that there is an integer $q>0$ such that $\tau_{k+q}=\tau_{k}+\omega, k \in \mathbb{N}$. Then

(1) species $x$ is permanent;

(2) any two positive solutions $x(t)$ and $\bar{x}(t)$ of (6) satisfy $\lim _{t \rightarrow+\infty}|x(t)-\bar{x}(t)|=0$.

Lemma 4 (see $[13,16])$. Consider the following single-species system with impulsive perturbations:

$$
\begin{gathered}
x^{\prime}(t)=x(t)[m(t)-n(t) x(t)], \quad t \neq \tau_{k}, k \in \mathbb{N}, \\
x\left(\tau_{k}^{+}\right)=\left(1+\alpha_{k}\right) x\left(\tau_{k}\right),
\end{gathered}
$$

where $x(0)>0, n(t)>0$ for all $t \geq 0, m(t), n(t)$ are continuous $\omega$-periodic functions and $\left\{\alpha_{k}\right\}$ is a real number sequence with $\alpha_{k}>-1$. Meanwhile, there exists an integer $q>0$ such that $\tau_{k+q}=\tau_{k}+\omega$ and $\alpha_{k+q}=\alpha_{k}$ for $k \in \mathbb{N}$. Then

(1) any solution $x(t)$ of (7) satisfies $\lim _{t \rightarrow+\infty} x(t)=0$ if $\prod_{k=1}^{q}\left(1+\alpha_{k}\right) \exp \left\{\int_{0}^{\omega} m(t) d t\right\}<1 ;$

(2) (7) has a unique positive w-periodic solution which is globally asymptotically stable if $\prod_{k=1}^{q}\left(1+\alpha_{k}\right) \exp \left\{\int_{0}^{\omega} m(t) d t\right\}>1$.

Lemma 5 (see [16]). Suppose that $v(t)$ is a continuous $\omega$ periodic function, where $\omega>0$ and $\int_{0}^{\omega} v(t) d t>0$. Then the following inequality

$$
\begin{array}{r}
\exp \{c(t-s)\} \leq \exp \left\{1+d \omega+\int_{s}^{t} v(r) d r\right\} \\
\text { for } t \geq s, t \longrightarrow+\infty
\end{array}
$$

holds, where $0<c \leq \min \left\{\int_{0}^{\omega} v(t) d t / \omega, 1 / \omega\right\}$, and $d=$ $\max _{t \in[0, \omega]}\{|v(t)|\}$.

\section{Main Results}

In this section, we will establish sufficient conditions for the permanence, global attractivity of positive solutions, and partial extinction of system (1), respectively. We first give the result on permanence.

\subsection{Permanence}

Theorem 6. If

$$
\begin{gathered}
\prod_{k=1}^{q}\left(1+\alpha_{k}\right) \exp \left\{\int _ { 0 } ^ { \omega } \left[r(t)-M_{2}\left(k_{1}(t)+\beta(t)\right)\right.\right. \\
\left.\left.-M_{3} a_{1}(t)\right] d t\right\}>1, \\
\prod_{k=1}^{q}\left(1+\gamma_{k}\right) \exp \left\{\int _ { 0 } ^ { \omega } \left[-d(t)+m_{1} c_{1}(t)\right.\right. \\
\left.\left.+m_{2} c_{2}(t)\right] d t\right\}>1
\end{gathered}
$$

hold, then system (1) is permanent, where $M_{2}, M_{3}, m_{1}, m_{2}$ are defined in (26), (29), (33), and (38), respectively.

Proof. For (1), it is easy to verify $S(t)>0, I(t)>0, P(t)>0$ for all $t>0$ if $S\left(0^{+}\right)=S(0)>0, I\left(0^{+}\right)=I(0)>0, P\left(0^{+}\right)=$ $P(0)>0$. To finish the proof of Theorem 6 , we consider the following two steps (i.e., (I) and (II)).

(I) Consider the uniformly ultimately upper boundary (or UUUB) of $S(t), I(t), P(t)$.

First of all, we discuss the UUUB of $S(t)$. It follows from the first equation of (1) and impulsive condition that

$$
\begin{gathered}
S^{\prime}(t) \leq r(t) S(t), \quad t \neq \tau_{k}, k \in \mathbb{N}, \\
S\left(\tau_{k}^{+}\right)=\left(1+\alpha_{k}\right) S\left(\tau_{k}\right), \\
S^{\prime}(t) \leq S(t)\left[r(t)-k_{1}(t) S(t)\right], \quad t \neq \tau_{k}, k \in \mathbb{N}, \\
S\left(\tau_{k}^{+}\right)=\left(1+\alpha_{k}\right) S\left(\tau_{k}\right) .
\end{gathered}
$$

Now, we consider two cases to obtain the UUUB of $S(t)$.

Case 1. Consider $\prod_{k=1}^{q}\left(1+\alpha_{k}\right) \exp \left\{\int_{0}^{\omega} r(t) d t\right\} \leq 1$.

For (11), applying Lemma 1, we have

$$
S(t) \leq S(0) \prod_{0<\tau_{k}<t}\left(1+\alpha_{k}\right) \exp \left\{\int_{0}^{t} r(s) d s\right\}
$$

When $t \in(n \omega,(n+1) \omega], n \in \mathbb{N} \cup\{0\}$, we set

$$
\begin{gathered}
\mathscr{A}=\max _{t \in[0, \omega]} \prod_{0<\tau_{k}<t}\left(1+\alpha_{k}\right), \\
\mathscr{R}=\max _{t \in(n \omega,(n+1) \omega]} \exp \left\{\int_{0}^{\omega} r(s) d s\right\} .
\end{gathered}
$$


It follows from (13) that

$$
\begin{aligned}
& S(t) \leq S(0) \prod_{0<\tau_{k}<n \omega}\left(1+\alpha_{k}\right) \exp \left\{\int_{0}^{n \omega} r(s) d s\right\} \\
& \times \prod_{n \omega \leq \tau_{k}<t}\left(1+\alpha_{k}\right) \exp \left\{\int_{n \omega}^{t} r(s) d s\right\} \\
& \leq S(0)\left(\prod_{k=1}^{q}\left(1+\alpha_{k}\right) \exp \left\{\int_{0}^{\omega} r(s) d s\right\}\right)^{n} \\
& \times \prod_{0<\tau_{k}<t-n \omega}\left(1+\alpha_{k}\right) \exp \left\{\int_{n \omega}^{t} r(s) d s\right\} \\
& \leq S(0)\left(\prod_{k=1}^{q}\left(1+\alpha_{k}\right) \exp \left\{\int_{0}^{\omega} r(s) d s\right\}\right)^{n} \mathscr{A} \mathscr{R} . \\
& \text { If } \prod_{k=1}^{q}\left(1+\alpha_{k}\right) \exp \left\{\int_{0}^{\omega} r(s) d s\right\}=1, \text { then } \\
& S(t) \leq S(0) \mathscr{A} \mathscr{R} .
\end{aligned}
$$

If $\prod_{k=1}^{q}\left(1+\alpha_{k}\right) \exp \left\{\int_{0}^{\omega} r(s) d s\right\}<1$, then

$$
\lim _{t \rightarrow+\infty} S(0)\left(\prod_{k=1}^{q}\left(1+\alpha_{k}\right) \exp \left\{\int_{0}^{\omega} r(s) d s\right\}\right)^{n} \mathscr{A} \mathscr{R}=0 .
$$

This fact implies that $\lim _{t \rightarrow+\infty} S(t)=0$. That is, there are a sufficient small constant $\sigma_{1}>0$ and $t_{1}>0$ such that

$$
S(t) \leq \sigma_{1}, \quad \text { for } t \geq t_{1} .
$$

Case 2. Consider $\prod_{k=1}^{q}\left(1+\alpha_{k}\right) \exp \left\{\int_{0}^{\omega} r(t) d t\right\}>1$.

It follows from (2) in Lemma 4 that the comparison system of (12)

$$
\begin{gathered}
s_{1}^{\prime}(t)=s_{1}(t)\left[r(t)-k_{1}(t) s_{1}(t)\right], \quad t \neq \tau_{k}, k \in \mathbb{N}, \\
s_{1}\left(\tau_{k}^{+}\right)=\left(1+\alpha_{k}\right) s_{1}\left(\tau_{k}\right)
\end{gathered}
$$

has a unique positive globally asymptotically stable $\omega$ periodic solution denoted by $\bar{s}_{1}(t)$. Let $s_{1}(t)$ be the solution of (19) with $s_{1}(0)=S(0)>0$. The asymptotic property of $\bar{s}_{1}(t)$ shows that there exist a sufficient small constant $\sigma_{2}>0$ and $t_{2}>0$ such that

$$
s_{1}(t) \leq \bar{s}_{1}(t)+\sigma_{2}, \quad \text { for } t \geq t_{2} .
$$

Applying the comparison theorem of impulsive differential equations, one has

$$
S(t) \leq \bar{s}_{1}(t)+\sigma_{2}, \quad \text { for } t \geq t_{2} .
$$

Equations (18) and (21) show that there must be $T_{1}=$ $\max \left\{t_{1}, t_{2}\right\}$ and $M_{1}=\max _{t \in[0, \omega]}\left\{S(0) \mathscr{A} \mathscr{R}, \sigma_{1}, \bar{s}_{1}(t)+\sigma_{2}\right\}>0$ such that

$$
S(t) \leq M_{1}, \quad \text { for } t \geq T_{1} \text {. }
$$

Next, we discuss the UUUB of $I(t)$. From the second equation of (1) and impulsive condition, for $t \geq T_{1}$, one has

$$
\begin{gathered}
I^{\prime}(t) \leq I(t)\left[M_{1} \beta(t)-k_{2}(t) I(t)\right], \quad t \neq \tau_{k}, k \in \mathbb{N}, \\
I\left(\tau_{k}^{+}\right)=I\left(\tau_{k}\right)+p .
\end{gathered}
$$

Using (2) in Lemma 3, we can see that the comparison system of (23)

$$
\begin{gathered}
i_{1}^{\prime}(t)=i_{1}(t)\left[M_{1} \beta(t)-k_{2}(t) i_{1}(t)\right], \quad t \neq \tau_{k}, k \in \mathbb{N}, \\
i_{1}\left(\tau_{k}^{+}\right)=i_{1}\left(\tau_{k}\right)+p
\end{gathered}
$$

is permanent, which implies that there are $M_{2}>0$ and $T_{2} \geq$ $T_{1}$ such that

$$
i_{1}(t) \leq M_{2}, \quad \text { for } t \geq T_{2} \text {. }
$$

Using the comparison theorem of impulsive differential equations, we get

$$
I(t) \leq M_{2}, \quad \text { for } t \geq T_{2} .
$$

Finally, we verify the UUUB of $P(t)$. For $t \geq T_{2}$, from the third equation of (1) and impulsive condition, we obtain

$$
\begin{gathered}
P^{\prime}(t) \leq P(t)\left[-d(t)+M_{1} c_{1}(t)+M_{2} c_{2}(t)\right], \quad t \neq \tau_{k}, k \in \mathbb{N} \\
P\left(\tau_{k}^{+}\right)=\left(1+\gamma_{k}\right) P\left(\tau_{k}\right) \\
P^{\prime}(t) \leq P(t)\left[-d(t)+M_{1} c_{1}(t)+M_{2} c_{2}(t)\right. \\
-b(t) P(t)], \quad t \neq \tau_{k}, \quad k \in \mathbb{N}, \\
P\left(\tau_{k}^{+}\right)=\left(1+\gamma_{k}\right) P\left(\tau_{k}\right) .
\end{gathered}
$$

Similar to the proof of the UUUB of $S(t)$, it follows from (10) that there exist $T_{3}>0$ and $M_{3}>0$ such that

$$
P(t) \leq M_{3}, \quad \text { for } t \geq T_{3} .
$$

(II) Consider the uniformly ultimately lower boundary (or UULB) of $S(t), I(t), P(t)$.

Firstly, we prove the UULB of $S(t)$. From (I), for $t \geq T_{3}$, one has

$$
\begin{aligned}
& S^{\prime}(t) \geq S(t)[ r(t)-M_{2}\left(k_{1}(t)+\beta(t)\right) \\
&\left.-M_{3} a_{1}(t)-k_{1}(t) S(t)\right], \quad t \neq \tau_{k}, k \in \mathbb{N}, \\
& S\left(\tau_{k}^{+}\right)=\left(1+\alpha_{k}\right) S\left(\tau_{k}\right) .
\end{aligned}
$$

By (2) in Lemma 4 and the assumption in (9), we know easily that the comparison system of (30)

$$
\begin{aligned}
& s_{2}^{\prime}(t)=s_{2}(t)\left[r(t)-M_{2}\left(k_{1}(t)+\beta(t)\right)\right. \\
&\left.-M_{3} a_{1}(t)-k_{1}(t) s_{2}(t)\right], \quad t \neq \tau_{k}, k \in \mathbb{N}, \\
& s_{2}\left(\tau_{k}^{+}\right)=\left(1+\alpha_{k}\right) s_{2}\left(\tau_{k}\right)
\end{aligned}
$$


has a unique positive globally asymptotically stable $\omega$ periodic solution denoted by $\bar{s}_{2}(t)$. Let $s_{2}(t)$ be the solution of (31) satisfying $s_{2}\left(T_{3}\right)=S\left(T_{3}\right)$. The asymptotic property of $\bar{s}_{2}(t)$ implies that there exist a sufficient small constant $\epsilon>0$ and $T_{4} \geq T_{3}$ such that

$$
s_{2}(t) \leq \bar{s}_{2}(t)-\epsilon, \quad \text { for } t \geq T_{4},
$$

where $\epsilon<(1 / 2) \min _{t \in[0, \omega]}\left\{\bar{s}_{2}(t)\right\}$. It follows from the comparison theorem of impulsive differential equations that

$$
S(t) \geq s_{2}(t)-\epsilon \geq \min _{t \in[0, \omega]}\left\{\bar{s}_{2}(t)\right\}-\epsilon \doteq m_{1}, \quad \text { for } t \geq T_{4} .
$$

Secondly, we prove the UULB of $I(t)$. Recall the above results, and it follows from (1) that for $t \geq T_{4}$,

$$
\begin{aligned}
& I^{\prime}(t) \geq I(t)\left[m_{1} \beta(t)-\left(M_{1}+M_{2}\right) k_{2}(t)-M_{3} a_{2}(t)\right] \\
& \geq I(t)\left[m_{1} \beta(t)-\left(M_{1}+M_{2}\right) k_{2}(t)\right. \\
& \quad\left.-M_{3} a_{2}(t)-\eta\right], \quad t \neq \tau_{k}, k \in \mathbb{N}, \\
& I\left(\tau_{k}^{+}\right)=I\left(\tau_{k}\right)+p,
\end{aligned}
$$

where the constant $\eta>0$ satisfies

$$
\int_{0}^{\omega}\left[m_{1} \beta(t)-\left(M_{1}+M_{2}\right) k_{2}(t)-M_{3} a_{2}(t)-\eta\right]<0 .
$$

From Lemma 2, we know that the comparison system of (34)

$$
\begin{aligned}
& i_{2}^{\prime}(t)= i_{2}(t)[ \\
& m_{1} \beta(t)-\left(M_{1}+M_{2}\right) k_{2}(t) \\
&\left.-M_{3} a_{2}(t)-\eta\right], \quad t \neq \tau_{k}, k \in \mathbb{N}, \\
& i_{2}\left(\tau_{k}^{+}\right)=i_{2}\left(\tau_{k}\right)+p
\end{aligned}
$$

has a unique positive globally asymptotically stable $\omega$ periodic solution denoted by $\bar{i}_{2}(t)$. The asymptotic property of $\bar{i}_{2}(t)$ implies that there are $T_{5} \geq T_{4}$ and a sufficient small constant $\delta>0$ such that

$$
i_{2}(t) \geq \bar{i}_{2}(t)-\delta, \quad \text { for } t \geq T_{5} \text {, }
$$

where $\delta<(1 / 2) \min _{t \in[0, \omega]}\left\{\bar{i}_{2}(t)\right\}$. Let $i_{2}(t)$ be the solution of (36) with $i_{2}\left(T_{5}\right)=I\left(T_{5}\right)$. Using the comparison theorem of impulsive differential equations, we have

$$
I(t) \geq \bar{i}_{2}(t)-\delta \geq \min _{t \in[0, \omega]}\left\{\bar{i}_{2}(t)\right\}-\delta \doteq m_{2}, \quad \text { for } t \geq T_{5} .
$$

Finally, we prove the UULB of $P(t)$. For $t \geq T_{5},(1),(33)$, and (38) reduce to

$$
\begin{gathered}
P^{\prime}(t) \geq P(t)\left[-d(t)+m_{1} c_{1}(t)+m_{2} c_{2}(t)\right. \\
-b(t) P(t)], \quad t \neq \tau_{k}, k \in \mathbb{N}, \\
P\left(\tau_{k}^{+}\right)=\left(1+\gamma_{k}\right) P\left(\tau_{k}\right) .
\end{gathered}
$$

Notice that the assumption in (10) is similar to the proof of the UULB of $S(t)$; we obtain that there are $T_{6} \geq T_{5}$ and $m_{3}>0$ such that

$$
P(t) \geq m_{3}, \quad \text { for } t \geq T_{6} \text {. }
$$

(I) and (II) yield

$$
\begin{array}{ll}
m_{1} \leq S(t) \leq M_{1}, & m_{2} \leq I(t) \leq M_{2}, \\
m_{3} \leq P(t) \leq M_{3}, & \text { for } t \geq T_{6},
\end{array}
$$

and hence system (1) is permanent. The proof is completed.

4.2. Global Attractivity. In this subsection, we will discuss the global attractivity of system (1) based on Theorem 6 .

Theorem 7. If there exist constants $\mu_{1}>0, \mu_{2}>0, \mu_{3}>0$ such that

$$
\begin{gathered}
\liminf _{t \rightarrow+\infty}\left\{\mu_{1} k_{1}(t)-\mu_{2}\left|\beta(t)-k_{2}(t)\right|-\mu_{3} c_{1}(t)\right\}>0, \\
\liminf _{t \rightarrow+\infty}\left\{\mu_{2} k_{2}(t)-\mu_{1}\left(k_{1}(t)+\beta(t)\right)-\mu_{3} c_{2}(t)\right\}>0, \\
\liminf _{t \rightarrow+\infty}\left\{\mu_{3} b(t)-\mu_{1} a_{1}(t)-\mu_{2} a_{2}(t)\right\}>0, \\
m_{2}+p=M_{2},
\end{gathered}
$$

hold, then any positive solution $\{S(t), I(t), P(t)\}$ of system (1) is globally attractive, where $M_{2}, m_{2}$ are defined in (26) and (38).

Proof. Suppose that $\{S(t), I(t), P(t)\}$ and $\left\{S^{*}(t), I^{*}(t), P^{*}(t)\right\}$ are any two positive solutions of system (1). It follows from Theorem 6 that there exists a large enough $t^{*}$ such that, for $t>t^{*} \geq T_{6}$,

$$
\begin{array}{ll}
m_{1} \leq S(t), & S^{*}(t) \leq M_{1}, \\
m_{2} \leq I(t), & I^{*}(t) \leq M_{2}, \\
m_{3} \leq P(t), & P^{*}(t) \leq M_{3} .
\end{array}
$$

Consider the following Lyapunov function:

$$
\begin{aligned}
V(t)= & \mu_{1}\left|\ln S(t)-\ln S^{*}(t)\right|+\mu_{2}\left|\ln I(t)-\ln I^{*}(t)\right| \\
& +\mu_{3}\left|\ln P(t)-\ln P^{*}(t)\right|
\end{aligned}
$$


where $\mu_{1}, \mu_{2}$, and $\mu_{3}$ are positive constants. Calculating and estimating the upper right derivative $D^{+} V(t)$ along the solutions of system (1), for $t>t^{*}$ and $t \neq \tau_{k}$, we obtain that

$$
\begin{aligned}
D^{+} V(t)= & \mu_{1} \operatorname{sgn}\left[S(t)-S^{*}(t)\right]\left[\frac{S^{\prime}(t)}{S(t)}-\frac{S^{* \prime}(t)}{S^{*}(t)}\right] \\
+ & \mu_{2} \operatorname{sgn}\left[I(t)-I^{*}(t)\right]\left[\frac{I^{\prime}(t)}{I(t)}-\frac{I^{* \prime}(t)}{I^{*}(t)}\right] \\
+ & \mu_{3} \operatorname{sgn}\left[P(t)-P^{*}(t)\right]\left[\frac{P^{\prime}(t)}{P(t)}-\frac{P^{* \prime}(t)}{P^{*}(t)}\right] \\
= & \mu_{1} \operatorname{sgn}\left[S(t)-S^{*}(t)\right] \\
\times & {\left[-k_{1}(t)\left(S(t)-S^{*}(t)\right)\right.} \\
& -\left(k_{1}(t)+\beta(t)\right)\left(I(t)-I^{*}(t)\right) \\
& \left.-a_{1}(t)\left(P(t)-P^{*}(t)\right)\right] \\
+ & \mu_{2} \operatorname{sgn}\left[I(t)-I^{*}(t)\right] \\
\times & {\left[\left(\beta(t)-k_{2}(t)\right)\left(S(t)-S^{*}(t)\right)\right.} \\
& -k_{2}(t)\left(I(t)-I^{*}(t)\right) \\
& \left.-a_{2}(t)\left(P(t)-P^{*}(t)\right)\right] \\
+ & \mu_{3} \operatorname{sgn}\left[P(t)-P^{*}(t)\right] \\
\times & {\left[c_{1}(t)\left(S(t)-S^{*}(t)\right)+c_{2}(t)\left(I(t)-I^{*}(t)\right)\right.} \\
& \left.-b(t)\left(P(t)-P^{*}(t)\right)\right] \\
\leq- & {\left[\mu_{1} k_{1}(t)-\mu_{2}\left|\beta(t)-k_{2}(t)\right|-\mu_{3} c_{1}(t)\right] } \\
\times & \left|S(t)-S^{*}(t)\right| \\
- & {\left[\mu_{2} k_{2}(t)-\mu_{1}\left(k_{1}(t)+\beta(t)\right)-\mu_{3} c_{2}(t)\right] } \\
\times & \left|I(t)-I^{*}(t)\right| \\
- & {\left[\mu_{3} b(t)-\mu_{1} a_{1}(t)-\mu_{2} a_{2}(t)\right] } \\
\times & \left|P(t)-P^{*}(t)\right| . \\
& \sin (t)
\end{aligned}
$$

Applying (43) and the differential mean value theorem, for any closed interval contained in $t \in\left(\tau_{k}, \tau_{k+1}\right], k=h, h+1, \ldots$, and $\tau_{h}>t^{*}$, we thus have

$$
\begin{aligned}
\frac{1}{M_{1}}\left|S(t)-S^{*}(t)\right| & \leq\left|\ln S(t)-\ln S^{*}(t)\right| \\
& \leq \frac{1}{m_{1}}\left|S(t)-S^{*}(t)\right|, \\
\frac{1}{M_{2}}\left|I(t)-I^{*}(t)\right| & \leq\left|\ln I(t)-\ln I^{*}(t)\right| \\
& \leq \frac{1}{m_{2}}\left|I(t)-I^{*}(t)\right|,
\end{aligned}
$$

$$
\begin{aligned}
\frac{1}{M_{3}}\left|P(t)-P^{*}(t)\right| & \leq\left|\ln P(t)-\ln P^{*}(t)\right| \\
& \leq \frac{1}{m_{3}}\left|P(t)-P^{*}(t)\right| .
\end{aligned}
$$

Hence, for $t \in\left(\tau_{k}, \tau_{k+1}\right], k=h, h+1, \ldots$, and $\tau_{h}>t^{*}$, from (45)-(46), we get

$$
\begin{aligned}
D^{+} V(t) \leq & -\left[\mu_{1} k_{1}(t)-\mu_{2}\left|\beta(t)-k_{2}(t)\right|-\mu_{3} c_{1}(t)\right] \\
& \times\left|S(t)-S^{*}(t)\right| \\
& -\left[\mu_{2} k_{2}(t)-\mu_{1}\left(k_{1}(t)+\beta(t)\right)-\mu_{3} c_{2}(t)\right] \\
& \times\left|I(t)-I^{*}(t)\right| \\
& -\left[\mu_{3} b(t)-\mu_{1} a_{1}(t)-\mu_{2} a_{2}(t)\right] \\
& \times\left|P(t)-P^{*}(t)\right| \\
\leq & -m_{1}\left[\mu_{1} k_{1}(t)-\mu_{2}\left|\beta(t)-k_{2}(t)\right|-\mu_{3} c_{1}(t)\right] \\
& \times\left|\ln S(t)-\ln S^{*}(t)\right| \\
& -m_{2}\left[\mu_{2} k_{2}(t)-\mu_{1}\left(k_{1}(t)+\beta(t)\right)-\mu_{3} c_{2}(t)\right] \\
& \times\left|\ln I(t)-\ln I^{*}(t)\right| \\
& -m_{3}\left[\mu_{3} b(t)-\mu_{1} a_{1}(t)-\mu_{2} a_{2}(t)\right] \\
& \times\left|\ln P(t)-\ln P^{*}(t)\right| \\
\leq & -\rho\left[\left|\ln S(t)-\ln S^{*}(t)\right|+\left|\ln I(t)-\ln I^{*}(t)\right|\right. \\
& \left.\quad+\left|\ln P(t)-\ln P^{*}(t)\right|\right]=-\rho V(t),
\end{aligned}
$$

where

$$
\begin{gathered}
\rho=\min _{t \in[0, \omega]}\left\{m_{1}\left[\mu_{1} k_{1}(t)-\mu_{2}\left|\beta(t)-k_{2}(t)\right|-\mu_{3} c_{1}(t)\right],\right. \\
m_{2}\left[\mu_{2} k_{2}(t)-\mu_{1}\left(k_{1}(t)+\beta(t)\right)-\mu_{3} c_{2}(t)\right], \\
\left.m_{3}\left[\mu_{3} b(t)-\mu_{1} a_{1}(t)-\mu_{2} a_{2}(t)\right]\right\}>0 .
\end{gathered}
$$

For $t=\tau_{k}, k \in \mathbb{N}$, one has

$$
\begin{aligned}
V\left(\tau_{k}^{+}\right)= & \mu_{1}\left|\ln S\left(\tau_{k}^{+}\right)-\ln S^{*}\left(\tau_{k}^{+}\right)\right| \\
& +\mu_{2}\left|\ln I\left(\tau_{k}^{+}\right)-\ln I^{*}\left(\tau_{k}^{+}\right)\right| \\
& +\mu_{3}\left|\ln P\left(\tau_{k}^{+}\right)-\ln P^{*}\left(\tau_{k}^{+}\right)\right| \\
= & \mu_{1}\left|\ln \left(1+\alpha_{k}\right) S\left(\tau_{k}\right)-\ln \left(1+\alpha_{k}\right) S^{*}\left(\tau_{k}\right)\right| \\
& +\mu_{2}\left|\ln \left(I\left(\tau_{k}\right)+p\right)-\ln \left(I^{*}\left(\tau_{k}\right)+p\right)\right| \\
& +\mu_{3}\left|\ln \left(1+\gamma_{k}\right) P\left(\tau_{k}\right)-\ln \left(1+\gamma_{k}\right) P^{*}\left(\tau_{k}\right)\right|
\end{aligned}
$$




$$
\begin{aligned}
= & \mu_{1}\left|\ln S\left(\tau_{k}\right)-\ln S^{*}\left(\tau_{k}\right)\right| \\
& +\left.\mu_{2} g^{\prime}(v)\right|_{v=\zeta_{k}}\left|I\left(\tau_{k}\right)-I^{*}\left(\tau_{k}\right)\right| \\
& +\mu_{3}\left|\ln P\left(\tau_{k}\right)-\ln P^{*}\left(\tau_{k}\right)\right| \\
= & \mu_{1}\left|\ln S\left(\tau_{k}\right)-\ln S^{*}\left(\tau_{k}\right)\right| \\
& +\frac{\mu_{2}}{\zeta_{k}+p}\left|I\left(\tau_{k}\right)-I^{*}\left(\tau_{k}\right)\right| \\
& +\mu_{3}\left|\ln P\left(\tau_{k}\right)-\ln P^{*}\left(\tau_{k}\right)\right|,
\end{aligned}
$$

where $\zeta_{k}$ is between $I\left(\tau_{k}\right)$ and $I^{*}\left(\tau_{k}\right), g(v)=\ln (v+p)$. It follows from (46) that

$$
\frac{\mu_{2}}{\zeta_{k}+p}\left|I\left(\tau_{k}\right)-I^{*}\left(\tau_{k}\right)\right| \leq \frac{\mu_{2} M_{2}}{m_{2}+p}\left|\ln I\left(\tau_{k}\right)-\ln I^{*}\left(\tau_{k}\right)\right|,
$$

which, together with (49), leads to

$$
\begin{aligned}
V\left(\tau_{k}^{+}\right) \leq & \mu_{1}\left|\ln S\left(\tau_{k}\right)-\ln S^{*}\left(\tau_{k}\right)\right| \\
& +\frac{\mu_{2} M_{2}}{m_{2}+p}\left|\ln I\left(\tau_{k}\right)-\ln I^{*}\left(\tau_{k}\right)\right| \\
& +\mu_{3}\left|\ln P\left(\tau_{k}\right)-\ln P^{*}\left(\tau_{k}\right)\right| \leq \lambda V\left(\tau_{k}\right),
\end{aligned}
$$

where $\lambda=\max \left\{\mu_{1}, \mu_{2} M_{2} /\left(m_{2}+p\right), \mu_{3}\right\}$. Combining (47) and (51), we have

$$
\begin{gathered}
D^{+} V(t) \leq-\rho V(t), \quad t \neq \tau_{k}, t>t^{*}, \\
V\left(\tau_{k}^{+}\right) \leq \lambda V\left(\tau_{k}\right), \quad \tau_{k}>t^{*}, k=h, h+1, \ldots
\end{gathered}
$$

From Lemma 1, for $t>\tau_{h}>t^{*},(52)$ yields

$$
V(t) \leq \lambda V\left(\tau_{h}^{+}\right) \exp \left\{-\int_{\tau_{h}}^{t} \rho d s\right\}=\lambda V\left(\tau_{h}^{+}\right) \exp \left\{-\rho\left(t-\tau_{h}\right)\right\} .
$$

Since $\tau_{h}$ is an impulsive point, we have from (43) and (44) that,

$$
\begin{aligned}
V\left(\tau_{h}^{+}\right)= & \mu_{1}\left|\ln S\left(\tau_{h}^{+}\right)-\ln S^{*}\left(\tau_{h}^{+}\right)\right| \\
& +\mu_{2}\left|\ln I\left(\tau_{h}^{+}\right)-\ln I^{*}\left(\tau_{h}^{+}\right)\right| \\
& +\mu_{3}\left|\ln P\left(\tau_{h}^{+}\right)-\ln P^{*}\left(\tau_{h}^{+}\right)\right| \\
\leq & \max \left\{2 \mu_{1}\left|\ln M_{1}\right|, 2 \mu_{1}\left|\ln m_{1}\right|\right\} \\
& +\max \left\{2 \mu_{2}\left|\ln \left(M_{2}+p\right)\right|, 2 \mu_{2}\left|\ln \left(m_{2}+p\right)\right|\right\} \\
& +\max \left\{2 \mu_{3}\left|\ln M_{3}\right|, 2 \mu_{3}\left|\ln m_{3}\right|\right\},
\end{aligned}
$$

which indicates that $V\left(\tau_{h}^{+}\right)$is bounded. As a consequence, we get

$$
V(t) \leq \lambda V\left(\tau_{h}^{+}\right) \exp \left\{-\rho\left(t-\tau_{h}\right)\right\} \longrightarrow 0, \quad \text { as } t \longrightarrow+\infty,
$$

and hence

$$
\begin{gathered}
\lim _{t \rightarrow+\infty}\left(\left|\ln S(t)-\ln S^{*}(t)\right|+\left|\ln I(t)-\ln I^{*}(t)\right|\right. \\
\left.+\left|\ln P(t)-\ln P^{*}(t)\right|\right)=0
\end{gathered}
$$

or equivalently

$$
\begin{aligned}
& \lim _{t \rightarrow+\infty}\left|\ln S(t)-\ln S^{*}(t)\right|=0, \\
& \lim _{t \rightarrow+\infty}\left|\ln I(t)-\ln I^{*}(t)\right|=0, \\
& \lim _{t \rightarrow+\infty}\left|\ln P(t)-\ln P^{*}(t)\right|=0,
\end{aligned}
$$

which, together with (46), yields

$$
\begin{aligned}
& \lim _{t \rightarrow+\infty} \frac{1}{M_{1}}\left|S(t)-S^{*}(t)\right|=0, \\
& \lim _{t \rightarrow+\infty} \frac{1}{M_{2}}\left|I(t)-I^{*}(t)\right|=0, \\
& \lim _{t \rightarrow+\infty} \frac{1}{M_{3}}\left|P(t)-P^{*}(t)\right|=0,
\end{aligned}
$$

that is,

$$
\begin{aligned}
& \lim _{t \rightarrow+\infty}\left|S(t)-S^{*}(t)\right|=0, \\
& \lim _{t \rightarrow+\infty}\left|I(t)-I^{*}(t)\right|=0, \\
& \lim _{t \rightarrow+\infty}\left|P(t)-P^{*}(t)\right|=0 .
\end{aligned}
$$

This completes the proof.

4.3. Partial Extinction. This section concerns the partial extinction of system (1). We will see that species $S, P$ tend to extinction while species $I$ stabilizes at a positive solution of an impulsive system.

Theorem 8. If

$$
\begin{gathered}
\prod_{k=1}^{q}\left(1+\alpha_{k}\right) \exp \left\{\int_{0}^{\omega} r(t) d t\right\}<1 \\
\prod_{k=1}^{q}\left(1+\gamma_{k}\right) \exp \left\{\int_{0}^{\omega}\left[-d(t)+M_{1}^{*} c_{1}(t)+M_{2}^{*} c_{2}(t)\right] d t\right\}<1
\end{gathered}
$$

hold, then any positive solution $\{S(t), I(t), P(t)\}$ of system (1) satisfies $\lim _{t \rightarrow+\infty} S(t)=0, \lim _{t \rightarrow+\infty}|I(t)-\Gamma(t)|=0$, $\lim _{t \rightarrow+\infty} P(t)=0$, where $M_{1}^{*}, M_{2}^{*}$ are defined in (65) and (67), respectively, and $\Gamma(t)$ is a positive solution of the impulsive system

$$
\begin{aligned}
\Gamma^{\prime}(t) & =-k_{2} \Gamma^{2}(t), \quad t \neq \tau_{k}, k \in \mathbb{N}, \\
\Gamma\left(\tau_{k}^{+}\right) & =\Gamma\left(\tau_{k}\right)+p .
\end{aligned}
$$




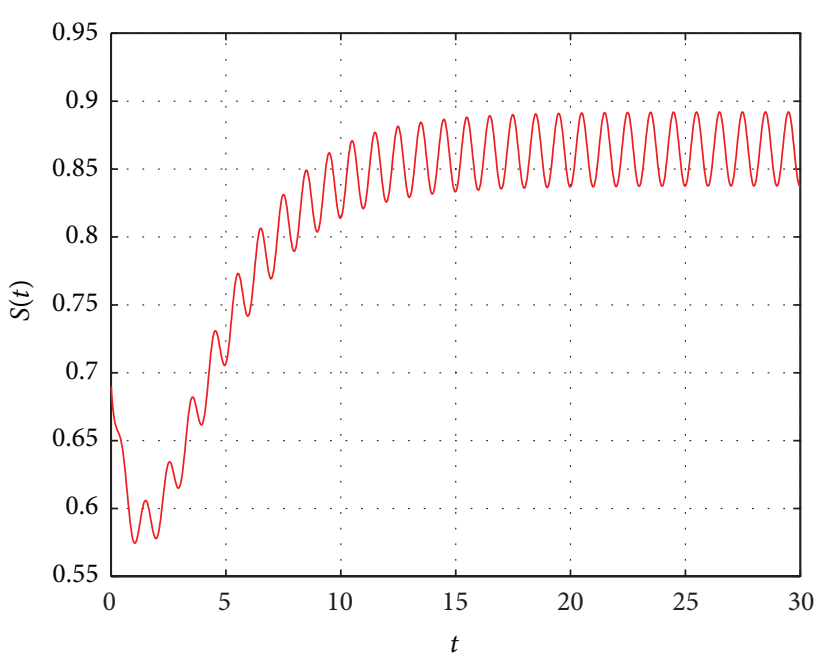

$-S(0)=0.69$

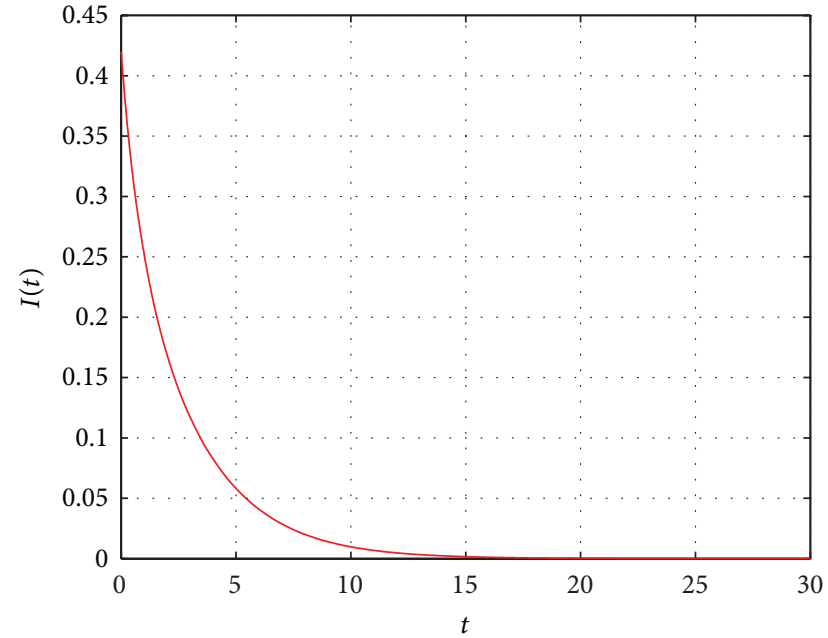

$I(0)=0.42$

(a)

(b)

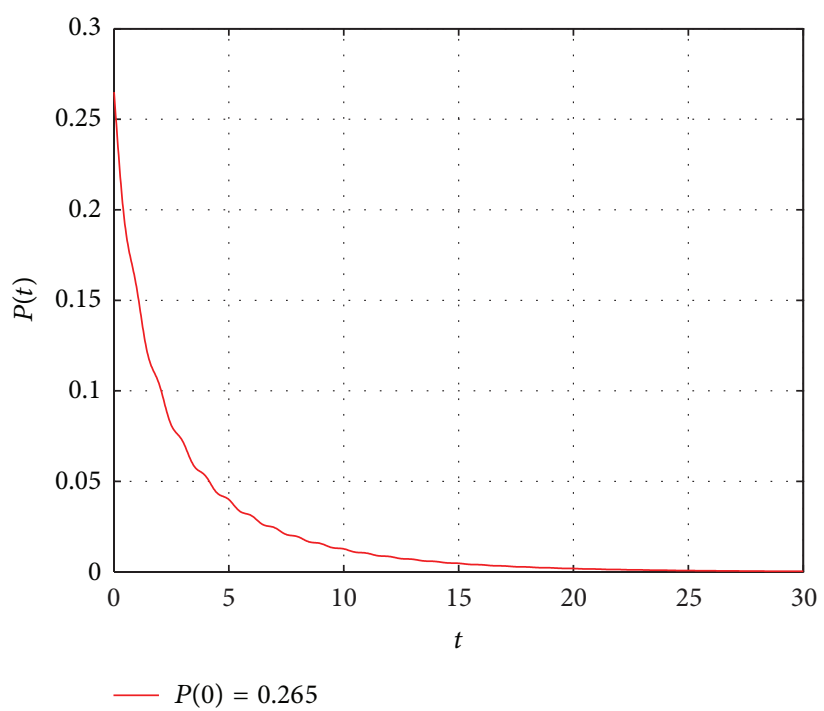

(c)

FIGURE 1: Partial extinction of system (80) with $\alpha_{k}=0, p=0$, and $\gamma_{k}=0$. (a) Time series of $S$ for $t \in[0,30]$. (b) Time series of $I$ for $t \in[0,30]$. (c) Time series of $P$ for $t \in[0,30]$.

Proof. We first focus on $S(t)$. We get from system (1) that

$$
\begin{aligned}
& S^{\prime}(t) \leq S(t)\left[r(t)-k_{1}(t) S(t)\right], \quad t \neq \tau_{k}, k \in \mathbb{N}, \\
& S\left(\tau_{k}^{+}\right)=\left(1+\alpha_{k}\right) S\left(\tau_{k}\right) .
\end{aligned}
$$

It follows from (60) and (1) in Lemma 4 that any positive solution of the comparison system of (63)

$$
\begin{aligned}
& s^{\prime}(t)=s(t)\left[r(t)-k_{1}(t) s(t)\right], \quad t \neq \tau_{k}, k \in \mathbb{N}, \\
& s\left(\tau_{k}^{+}\right)=\left(1+\alpha_{k}\right) s\left(\tau_{k}\right)
\end{aligned}
$$

satisfies $\lim _{t \rightarrow+\infty} s(t)=0$. By the comparison theorem of impulsive differential equations we can obtain that $\lim _{t \rightarrow+\infty} S(t)=0$. This fact implies that there exist a sufficient small constant $M_{1}^{*}>0$ and $\widehat{t}_{1}>0$ such that

$$
S(t) \leq M_{1}^{*}, \quad \text { for } t \geq \widehat{t}_{1} .
$$

Next, from system (1), we obtain that, for $t \geq \widehat{t}_{1}$,

$$
\begin{gathered}
I^{\prime}(t) \leq I(t)\left[M_{1}^{*} \beta(t)-k_{2}(t) I(t)\right], \quad t \neq \tau_{k}, k \in \mathbb{N}, \\
I\left(\tau_{k}^{+}\right)=I\left(\tau_{k}\right)+p .
\end{gathered}
$$

Similar to (23) - (26), we get that there exist a constant $M_{2}^{*}>0$ and $\widehat{t}_{2} \geq \widehat{t}_{1}$ such that

$$
I(t) \leq M_{2}^{*}, \quad \text { for } t \geq \widehat{t}_{2} .
$$




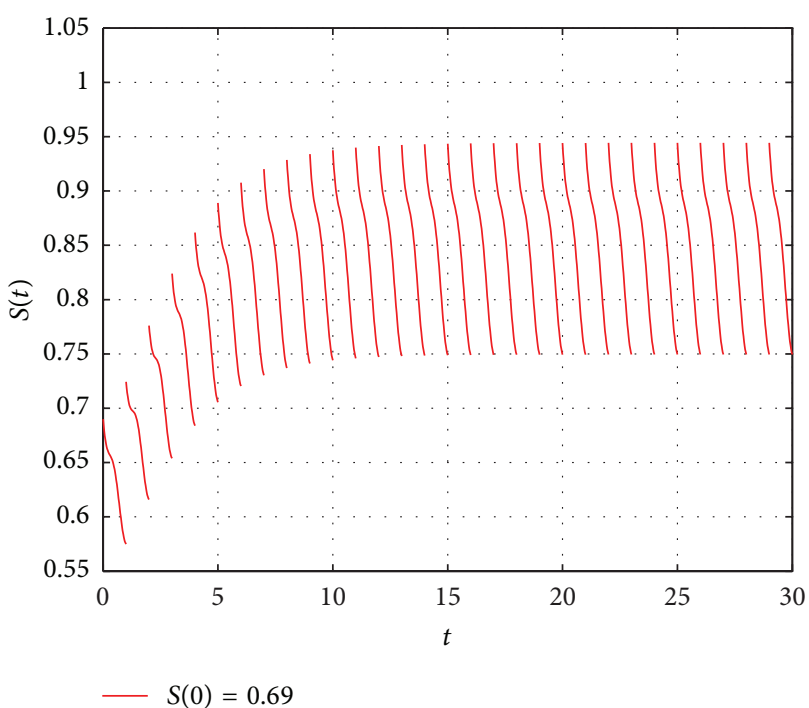

(a)

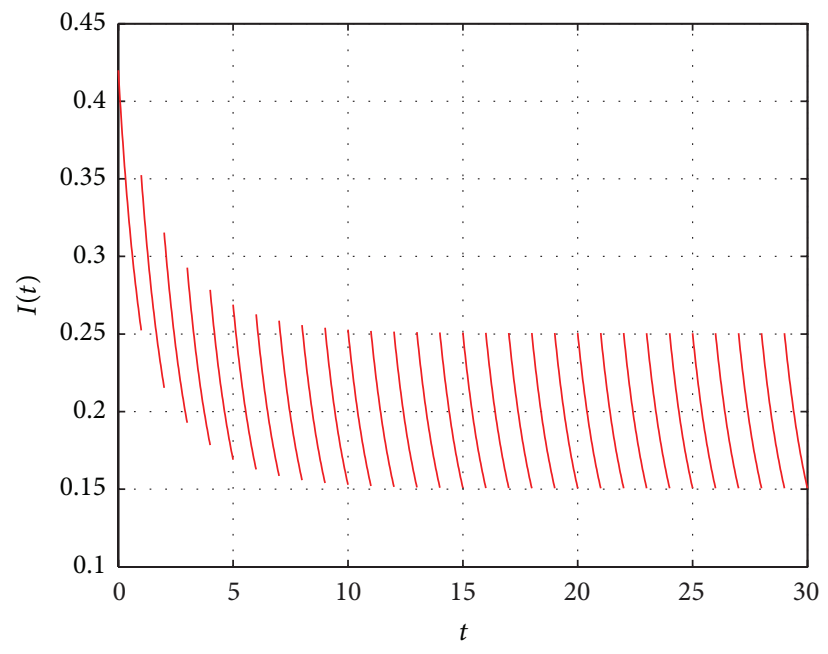

$I(0)=0.42$

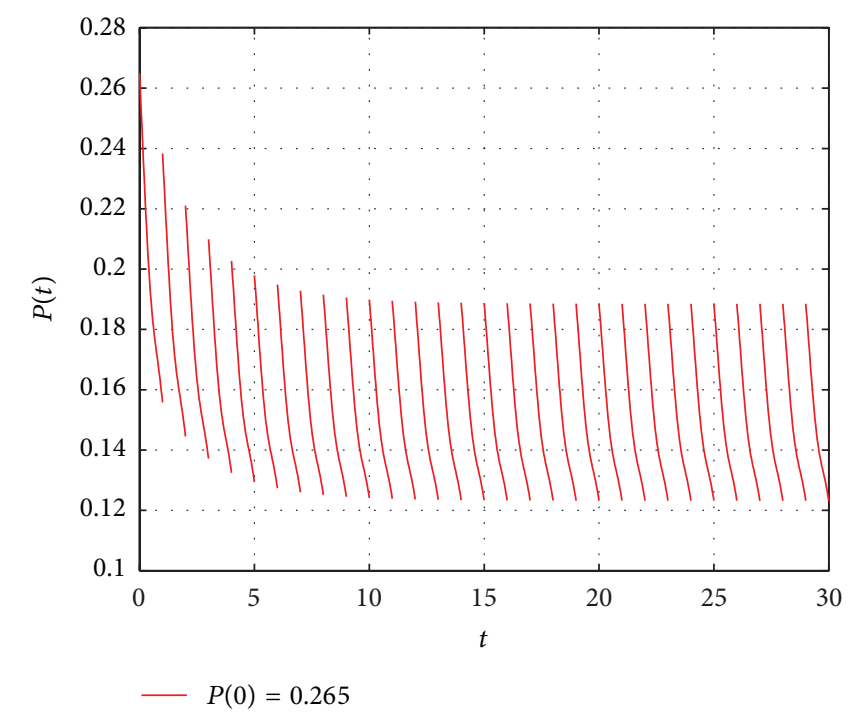

(c)

Figure 2: Permanence of system (80) with $\alpha_{k}=0.26, p=0.1$, and $\gamma_{k}=0.53$. (a) Time series of $S$ for $t \in[0,30]$. (b) Time series of $I$ for $t \in[0,30]$. (c) Time series of $P$ for $t \in[0,30]$.

From system (1), (65), and (67), we have

$$
\begin{gathered}
P^{\prime}(t) \leq P(t)\left[-d(t)+M_{1}^{*} c_{1}(t)+M_{2}^{*} c_{2}(t)\right. \\
-b(t) P(t)], \quad t \neq \tau_{k}, k \in \mathbb{N}, \\
P\left(\tau_{k}^{+}\right)=\left(1+\gamma_{k}\right) P\left(\tau_{k}\right) .
\end{gathered}
$$

Similar to $S(t)$, when the assumption (61) holds, a simple proof can verify $\lim _{t \rightarrow+\infty} P(t)=0$. This fact implies that there are a sufficient small constant $M_{3}^{*}>0$ and $\widehat{t}_{3} \geq \widehat{t}_{2}$ such that

$$
P(t) \leq M_{3}^{*}, \quad \text { for } t \geq \widehat{t}_{3} \text {. }
$$

From system (1), (65), and (69), we obtain that for $t \geq \widehat{t}_{3}$

$$
\begin{array}{r}
I^{\prime}(t) \geq I(t)\left[-M_{1}^{*} k_{2}(t)-M_{3}^{*} a_{2}(t)-k_{2}(t) I(t)\right], \\
t \neq \tau_{k}, k \in \mathbb{N}, \\
I\left(\tau_{k}^{+}\right)=I\left(\tau_{k}\right)+p .
\end{array}
$$

Similar to (23)-(26), we can obtain that there exist a constant $m_{2}^{*}>0$ and $T^{*} \geq \widehat{t}_{3}$ such that

$$
I(t) \geq m_{2}^{*}, \quad \text { for } t \geq T^{*},
$$

which, together with (67), leads to

$$
m_{2}^{*} \leq I(t) \leq M_{2}^{*}, \quad \text { for } t \geq T^{*} .
$$




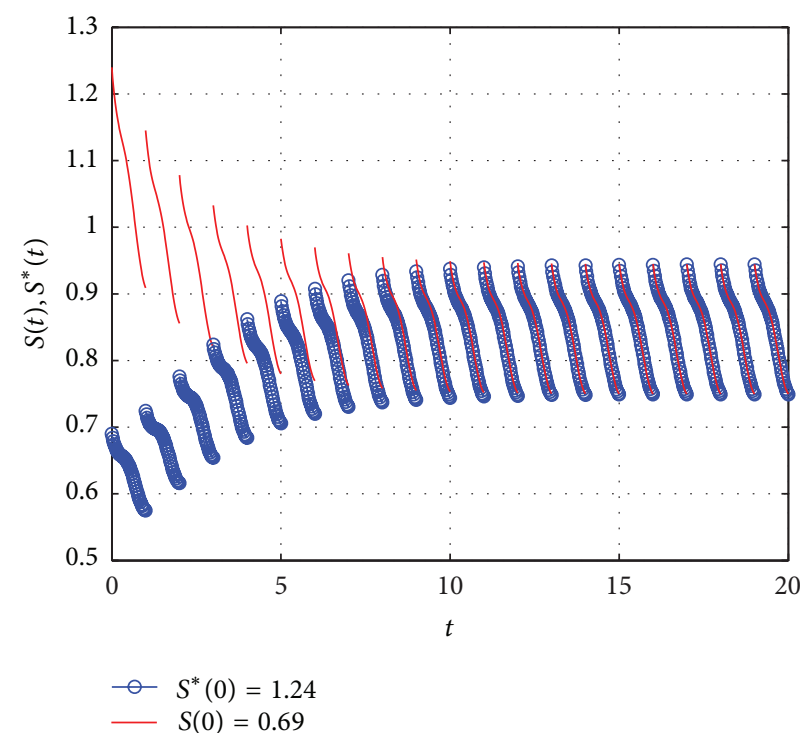

(a)

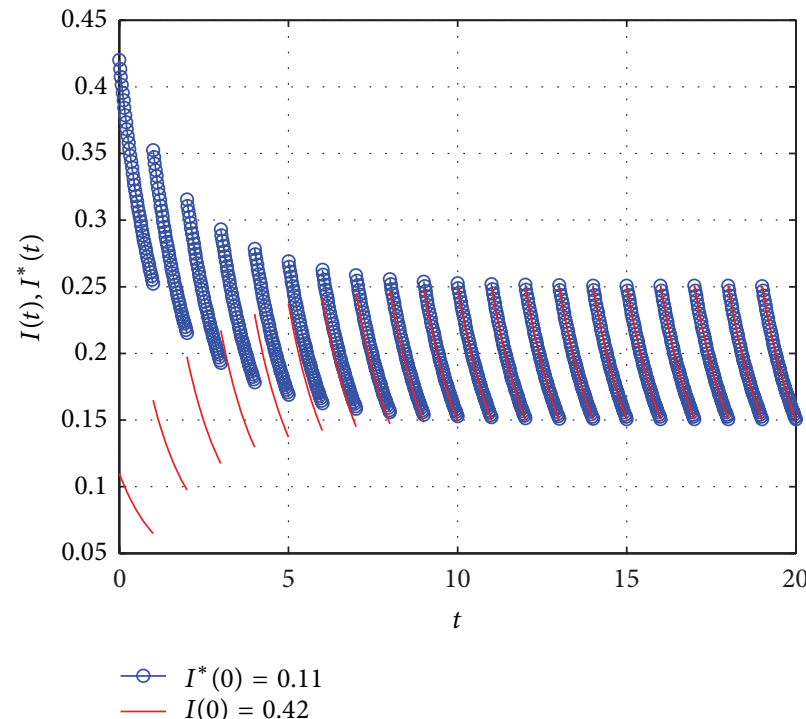

(b)

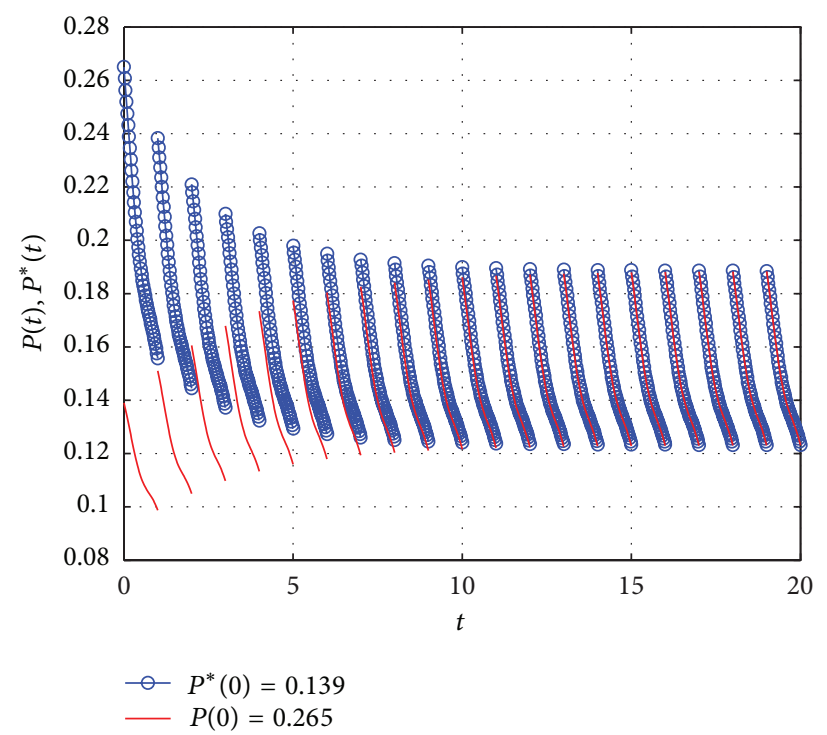

(c)

Figure 3: Global attractivity of system (80) with $\alpha_{k}=0.26, p=0.1$, and $\gamma_{k}=0.53$. (a) Positive solution $S(t)$ with $S(0)=0.69$ tends to the other positive solution $S^{*}(t)$ with $S^{*}(0)=1.24$ for $t \in[0,20]$. (b) Positive solution $I(t)$ with $I(0)=0.42$ tends to the other positive solution $I(t)$ with $I^{*}(0)=0.11$ for $t \in[0,20]$. (c) Positive solution $P(t)$ with $P(0)=0.265$ tends to the other positive solution $P^{*}(t)$ with $P^{*}(0)=0.139$ for $t \in[0,20]$.

Based on the above discussion, we will investigate the global attractivity of $I(t)$. Let

$$
Z(t)=I(t)-\Gamma(t) .
$$

Then,

$$
\begin{aligned}
Z^{\prime}(t)= & -k_{2}(t)(I(t)+\Gamma(t)) Z(t) \\
& +\left(\beta(t)-k_{2}(t)\right) S(t) I(t) \\
& -a_{2}(t) I(t) P(t), \quad t \neq \tau_{k}, k \in \mathbb{N}, \\
Z\left(\tau_{k}^{+}\right)= & \left(I\left(\tau_{k}\right)+p\right)-\left(\Gamma\left(\tau_{k}\right)+p\right)=Z\left(\tau_{k}\right) .
\end{aligned}
$$

Clearly, $Z(t)$ is continuous. Recalling (74) and using the formula of solutions of first-order linear differential equation, we get, for $t \geq T^{*}$,

$$
\begin{aligned}
Z(t)= & Z\left(T^{*}\right) \exp \left\{\int_{T^{*}}^{t}\left[-k_{2}(v)(I(v)+\Gamma(v))\right] d v\right\} \\
& +\int_{T^{*}}^{t}\left[\left(\beta(v)-k_{2}(v)\right) S(v) I(v)-a_{2}(v) I(v) P(v)\right] \\
& \quad \times \exp \left\{\int_{v}^{t}\left[-k_{2}(s)(I(s)+\Gamma(s))\right] d s\right\} d v,
\end{aligned}
$$




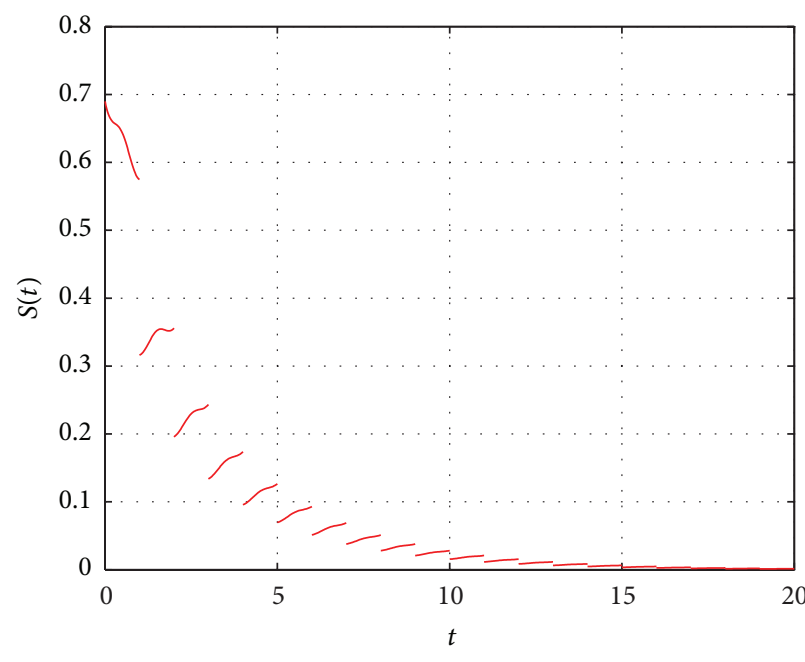

$-S(0)=0.69$

(a)

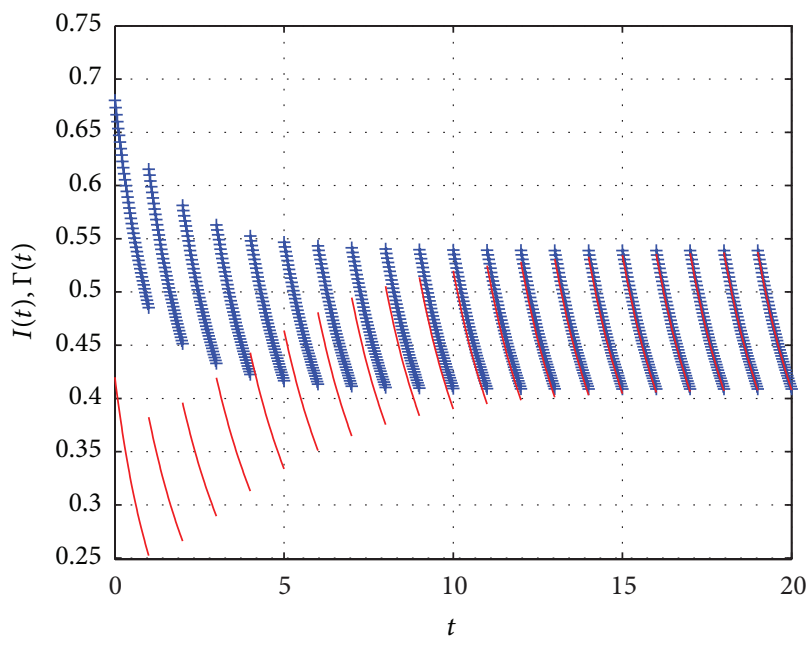

— $\Gamma(0)=0.68$

$I(0)=0.42$

(c)

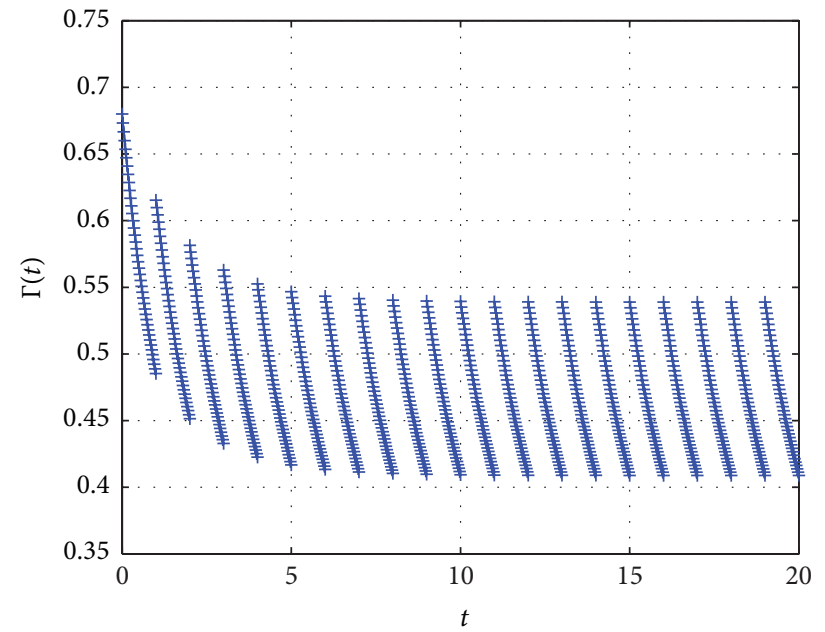

$\longrightarrow \Gamma(0)=0.68$

(b)

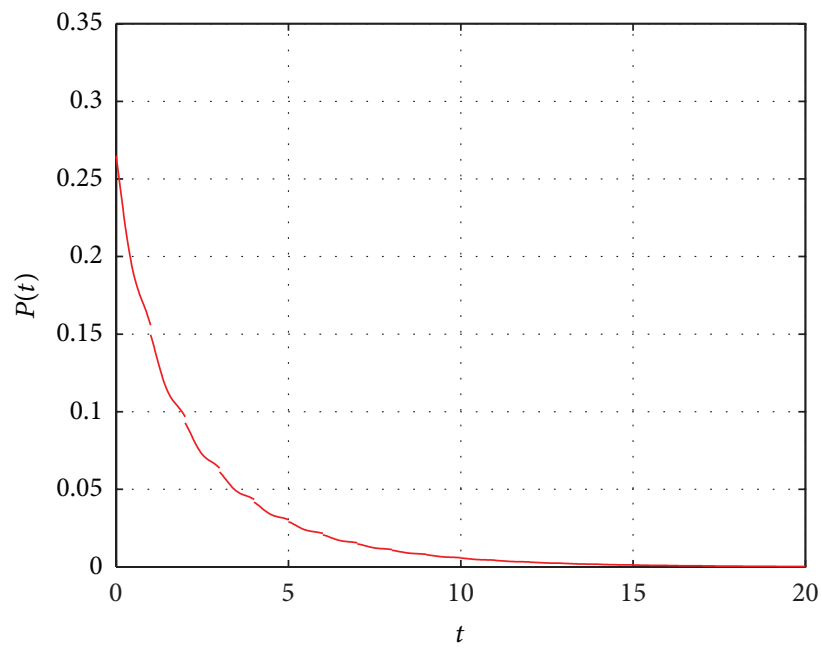

- $P(0)=0.265$

Figure 4: Partial extinction of system (80) with $\alpha_{k}=-0.45, p=0.13$, and $\gamma_{k}=-0.04$. (a) Time series of $S$ for $t \in[0,20]$. (b) Time series of $\Gamma$ for $t \in[0,20]$. (c) Time series of $\Gamma$ and $I$ for $t \in[0,20]$. (d) Time series of $P$ for $t \in[0,20]$.

Furthermore, applying Lemma 1, one obtains

$$
\begin{gathered}
|Z(t)| \leq\left|Z\left(T^{*}\right)\right| \exp \left\{\int_{T^{*}}^{t}\left[-k_{2}(v)(I(v)+\Gamma(v))\right] d v\right\} \\
+\int_{T^{*}}^{t}\left[\left|\beta(v)-k_{2}(v)\right| S(v) I(v)+a_{2}(v) I(v) P(v)\right] \\
\times \exp \left\{\int_{v}^{t}\left[-k_{2}(s)(I(s)+\Gamma(s))\right] d s\right\} d v, \\
\leq\left|Z\left(T^{*}\right)\right| \exp \left\{-m_{2}^{*} \int_{T^{*}}^{t} k_{2}(v) d v\right\}
\end{gathered}
$$

$$
\begin{aligned}
& +M_{2}^{*} \int_{T^{*}}^{t}\left[\left(\beta^{U}+k_{2}^{U}\right) S(v)+a_{2}^{U} P(v)\right] \\
& \quad \times \exp \left\{-m_{2}^{*} \int_{v}^{t} k_{2}(s) d s\right\} d v, \\
& \leq\left|Z\left(T^{*}\right)\right| \exp \left\{1+m_{2}^{*} k_{2}^{U} \omega-\mathscr{K}\left(t-T^{*}\right)\right\} \\
& +M_{2}^{*} \exp \left\{1+m_{2}^{*} k_{2}^{U} \omega\right\} \\
& \times \int_{T^{*}}^{t}\left[\left(\beta^{U}+k_{2}^{U}\right) S(v)+a_{2}^{U} P(v)\right] \\
& \times \exp \{\mathscr{K}(v-t)\} d v,
\end{aligned}
$$


where

$$
\begin{gathered}
k_{2}^{U}=\max _{t \in[0, \omega]}\left\{k_{2}(t)\right\}, \\
\beta^{U}=\max _{t \in[0, \omega]}\{\beta(t)\}, \\
a_{2}^{U}=\max _{t \in[0, \omega]}\left\{a_{2}(t)\right\}, \\
0<\mathscr{K}<\min \left\{\frac{\int_{0}^{\omega} m_{2}^{*} k_{2}(t) d t}{\omega}, \frac{1}{\omega}\right\} .
\end{gathered}
$$

Notice that $\lim _{t \rightarrow+\infty} S(t)=0, \lim _{t \rightarrow+\infty} P(t)=0$, and thus a calculation shows that

$$
\begin{aligned}
& \lim _{t \rightarrow+\infty} \int_{T^{*}}^{t} S(v) \exp \{\mathscr{K}(v-t)\} d v=0, \\
& \lim _{t \rightarrow+\infty} \int_{T^{*}}^{t} P(v) \exp \{\mathscr{K}(v-t)\} d v=0 .
\end{aligned}
$$

Hence,

$$
\lim _{t \rightarrow+\infty} \int_{T^{*}}^{t}\left[\left(\beta^{U}+k_{2}^{U}\right) S(v)+a_{2}^{U} P(v)\right] \exp \{\mathscr{K}(v-t)\} d v=0 .
$$

Combining (76) and (79), we obtain that $\lim _{t \rightarrow+\infty}|Z(t)|=0$, which implies $\lim _{t \rightarrow+\infty}|I(t)-\Gamma(t)|=0$. This completes the proof.

\section{Examples and Numerical Simulations}

In this paper, we investigate the dynamic behaviors of a periodic predator-prey system subject to impulsive perturbations, in which disease only spreads among the prey species. A good understanding of the permanence, global attractivity, and partial extinction of the above system is obtained. Our three main results (i.e., Theorems 6, 7, and 8) show that the impulsive perturbations play important roles in shaping the dynamics. To substantiate the theoretical results, we consider the following system:

$$
\begin{aligned}
S^{\prime}(t)=S(t) & {[0.83+0.2 \sin 2 \pi t-(0.96+0.01 \cos 2 \pi t)} \\
\times & (S(t)+I(t))-(0.19+0.01 \sin 2 \pi t) P(t) \\
& -(0.17+0.02 \sin 2 \pi t) I(t)] \\
I^{\prime}(t)=I(t) & {[(0.17+0.02 \sin 2 \pi t) S(t)} \\
- & (0.59+0.02 \sin 2 \pi t)(S(t)+I(t))
\end{aligned}
$$

$$
\begin{aligned}
&-(0.26+0.02 \cos 2 \pi t) P(t)], \\
& P^{\prime}(t)=P(t)[-(0.32+0.18 \sin 2 \pi t) \\
&-(1.78+0.05 \cos 2 \pi t) P(t) \\
&+(0.16+0.02 \sin 2 \pi t) S(t) \\
&+(0.12+0.02 \sin 2 \pi t) I(t)], \\
& t \neq \tau_{k}, \\
& S\left(\tau_{k}^{+}\right)=\left(1+\alpha_{k}\right) S\left(\tau_{k}\right), \\
& I\left(\tau_{k}^{+}\right)=I\left(\tau_{k}\right)+p, \\
& P\left(\tau_{k}^{+}\right)=\left(1+\gamma_{k}\right) P\left(\tau_{k}\right), \\
& t=\tau_{k}, k \in \mathbb{N} .
\end{aligned}
$$

Obviously, the period $\omega=1$. Let $q=1, \tau_{k}=k \in \mathbb{N}$; then, $\tau_{k+1}=\tau_{k}+1$. When $\alpha_{k}=0, p=0, \gamma_{k}=0$, from Figures $1(\mathrm{a})-1(\mathrm{c})$, that species $S$ of system (80) is permanent while $I$, $P$ tend to extinction.

Provided that all the other coefficients remain unchanged, we choose $\alpha_{k}=0.26, p=0.1$, and $\gamma_{k}=0.53$, a calculation showing that the assumptions of Theorem 6 hold. So species $S, I, P$ are permanent (see Figures 2(a)$2(c)$ ), and moreover, we can prove that the assumptions of Theorem 7 are satisfied, so system (80) is globally attractive. From Figures 3(a)-3(c), it is true that the positive solution $\{S(t), I(t), P(t)\}$ with $\{S(0), I(0), P(0)\}=\{0.69,0.42,0.265\}$ tends to the other positive solution $\left\{S^{*}(t), I^{*}(t), P(t)\right\}$ with $\left\{S^{*}(0), I^{*}(0), P^{*}(0)\right\}=\{1.24,0.11,0.139\}$. To verify partial extinction we choose $\alpha_{k}=-0.45, p=0.13$, and $\gamma_{k}=-0.04$; system (62) with $\Gamma(0)=0.68$ has a positive solution $\Gamma(t)$ (see Figure 4(b)). We can see that the assumptions of Theorem 8 hold, so species $I$ stabilizes at a certain solution of a impulsive system (see Figures 4(b) and 4(c)) while species $S, P$ tend towards extinction (see Figures 4(a) and 4(d)). The above facts demonstrate that the use of impulsive control strategy can change the dynamic behaviors of the system, and hence a suitable harvesting or stocking policy is important.

\section{Conflict of Interests}

The authors declare that there is no conflict of interests regarding the publication of this paper.

\section{Acknowledgments}

The work is supported by the National Natural Science Foundation of China (no. 11261017), the Key Project of Chinese Ministry of Education (no. 212111, 210134), and the Key subject of Hubei Province (Forestry). The authors would like to thank the referees for their valuable comments and suggestions that greatly improved the presentation of this work. 


\section{References}

[1] R. M. Anderson and R. M. May, Population Biology of Infectious Disease, Springer, Berlin, Germany, 1982.

[2] Y. Xiao and L. Chen, "Modeling and analysis of a predator-prey model with disease in the prey," Mathematical Biosciences, vol. 171, no. 1, pp. 59-82, 2001.

[3] B. Mukhopadhyay and R. Bhattacharyya, "Role of predator switching in an eco-epidemiological model with disease in the prey," Ecological Modelling, vol. 220, no. 7, pp. 931-939, 2009.

[4] G. P. Hu and X. L. Li, "Stability and Hopf bifurcation for a delayed predator-prey model with disease in the prey," Chaos, Solitons \& Fractals, vol. 45, no. 3, pp. 229-237, 2012.

[5] G. P. Samanta, "Analysis of a delay nonautonomous predatorprey system with disease in the prey," Nonlinear Analysis: Modelling and Control, vol. 15, no. 1, pp. 97-108, 2010.

[6] A. J. Nicholson, "An outline of the dynamics of the animal populations," Australian Journal of Zoology, vol. 2, no. 1, pp. 965, 1954.

[7] A. Lakmeche and O. Arino, "Bifurcation of non trivial periodic solutions of impulsive differential equations arising chemotherapeutic treatment," Dynamics of Continuous, Discrete and Impulsive Systems, vol. 7, no. 2, pp. 265-287, 2000.

[8] A. D'Onofrio, "On pulse vaccination strategy in the SIR epidemic model with vertical transmission," Applied Mathematics Letters, vol. 18, no. 7, pp. 729-732, 2005.

[9] M. Choisy, J. F. Guégan, and P. Rohani, "Dynamics of infectious diseases and pulse vaccination: teasing apart the embedded resonance effects," Physica D, vol. 223, no. 1, pp. 26-35, 2006.

[10] M. Liu, Z. Jin, and M. Haque, "An impulsive predator-prey model with communicable disease in the prey species only," Nonlinear Analysis: Real World Applications, vol. 10, no. 5, pp. 3098-3111, 2009.

[11] R. Shi, X. Jiang, and L. Chen, "A predator-prey model with disease in the prey and two impulses for integrated pest management," Applied Mathematical Modelling, vol. 33, no. 5, pp. 2248-2256, 2009.

[12] V. Lakshmikantham, D. D. Bainnov, and P. S. Simeonov, Theory of Impulsive Differential Equations, vol. 6 of Series in Modern Applied Mathematics, World Scientific, Singapore, 1989.

[13] Z. Liu, J. Wu, and R. A. Cheke, "Coexistence and partial extinction in a delay competitive system subject to impulsive harvesting and stocking," IMA Journal of Applied Mathematics, vol. 75, no. 5, pp. 777-795, 2010.

[14] W. Wang, J. Shen, and J. J. Nieto, "Permanence and periodic solution of predator-prey system with Holling type functional response and impulses," Discrete Dynamtics in Nature and Society, vol. 2007, Article ID 521729, 15 pages, 2007.

[15] Z. Liu, Y. Chen, Z. He, and J. Wu, "Permanence in a periodic delay logistic system subject to constant impulsive stocking," Mathematical Methods in the Applied Sciences, vol. 33, no. 8, pp. 985-993, 2010.

[16] W. Wang, J. Shen, and Z. Luo, "Partial survival and extinction in two competing species with impulses," Nonlinear Analysis: Real World Applications, vol. 10, no. 3, pp. 1243-1254, 2009. 


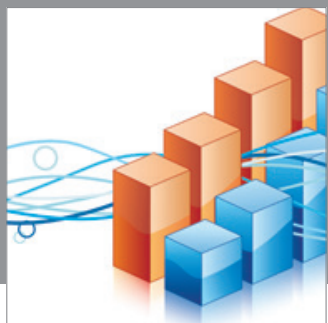

Advances in

Operations Research

mansans

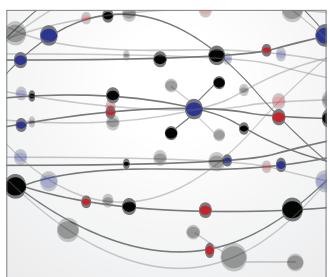

The Scientific World Journal
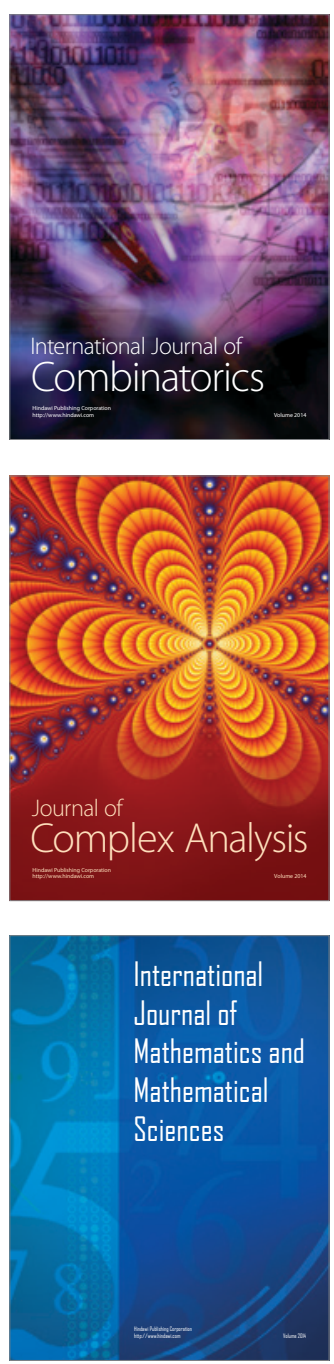
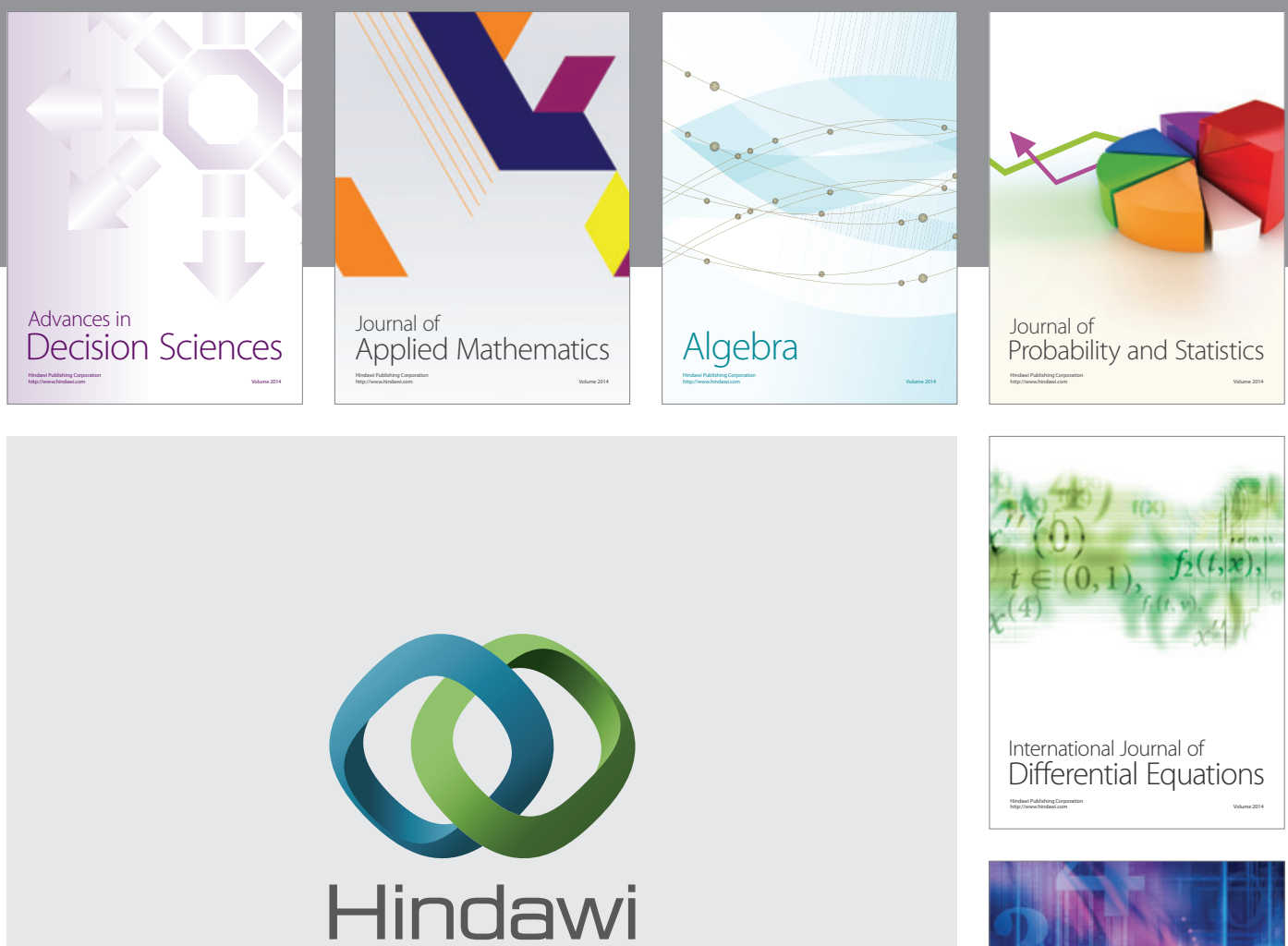

Submit your manuscripts at http://www.hindawi.com
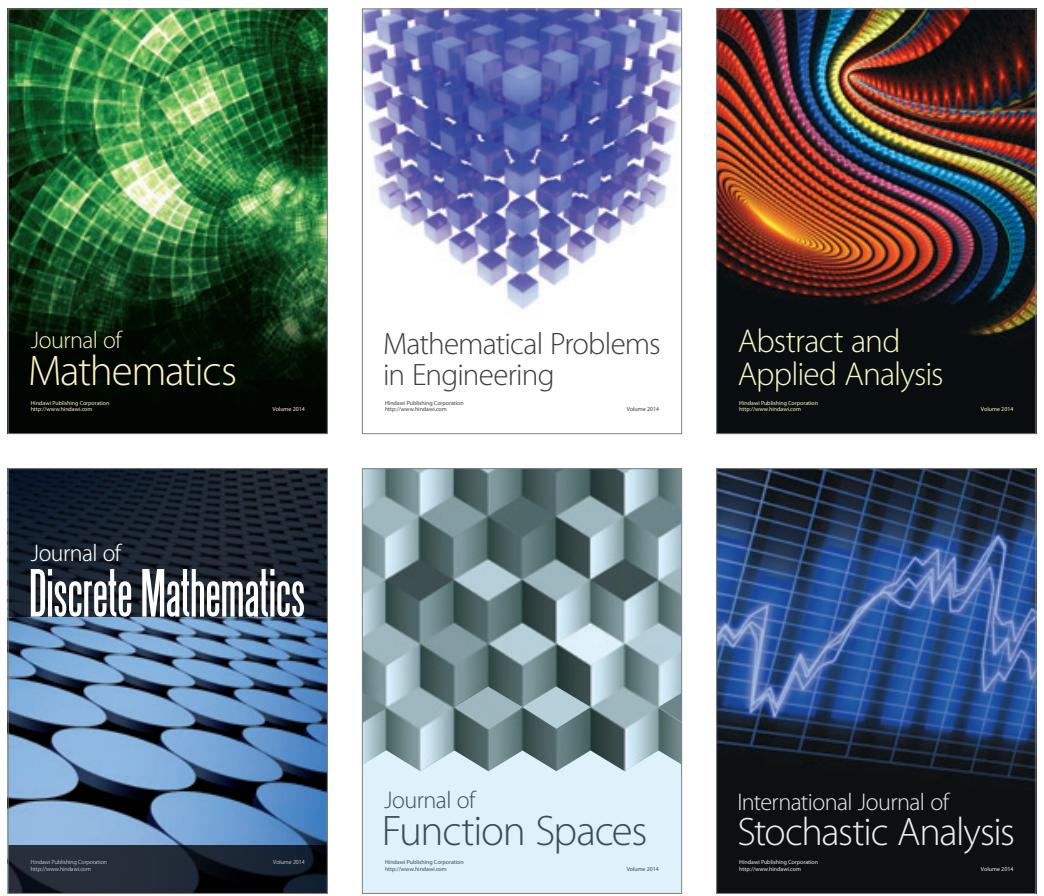

Journal of

Function Spaces

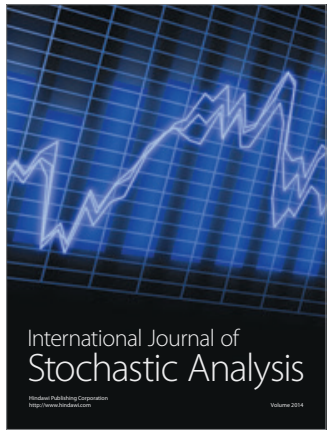

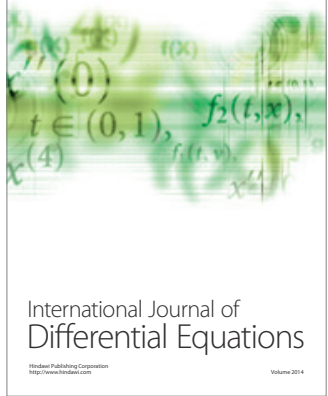
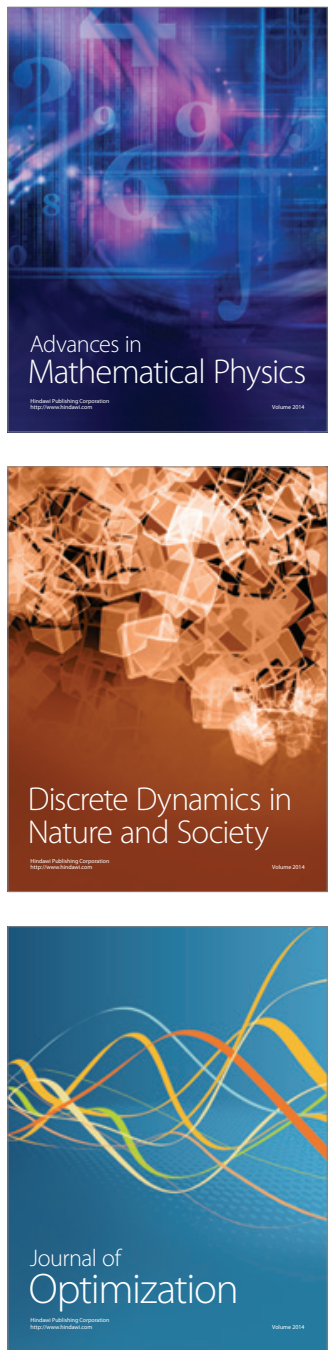